\title{
HUBUNGAN ANTARA SKOR IPSS DAN SKOR IIEF PADA PASIEN BPH DENGAN GEJALA LUTS YANG BEROBAT DI POLI BEDAH RSUP PROF. DR. R. D. KANDOU MANADO
}

\author{
${ }^{1}$ Margali Asalia \\ ${ }^{2}$ Richard Monoarfa \\ ${ }^{2}$ Harsali F. Lampus \\ ${ }^{1}$ Kandidat skripsi Fakultas Kedokteran Universitas Sam Ratulangi \\ ${ }^{2}$ Bagian Bedah RSUP Prof.Dr. R.D. Kandou Manado \\ Email: amargali11_252@yahoo.com
}

\begin{abstract}
Lower urinary tract symptoms (LUTS) due to benign prostatic hyperplasia (BPH) are common in elderly men. In addition to LUTS, patients with BPH also often experience erectile dysfunction (ED). According to the data obtained from $30 \mathrm{BPH}$ patients with symptoms of LUTS using the international prostate symptoms score (IPSS), 53.3\% had symptoms of LUTS with a severe degree, and based on the international index of erectile function (IIEF), BPH patients with LUTS symptoms and ED were found to have erectile function (EF) as much as $26.7 \%$ with a mild and severe degree, orgasmic function (OF) as much as $40 \%$ with a severe degree, sexual intercourse function (SI) as much as $46.7 \%$ with a mild-to-moderate degree, sexual satisfaction (SS) as much as $33.3 \%$ with a severe degree and overall satisfaction (OS) as much as $43.3 \%$ with a mild degree. In this study, the investigators wanted to examine the relationship between the IPSS with the IIEF scores in BPH patients with symptoms of LUTS in the outpatient surgery department of Prof. Dr R. D. Kandou General Hospital Manado. Based on the results of the spearman correlation test, relationship between the IPSS with the IIEF score yielded EF (R: 0.372), OF (R: 389), SI (R: 0.129), SS (R: 0.351), OS (R: 0, 84). These results suggest the presence of a relationship between IPSS and IIEF scores.
\end{abstract}

Keywords: IPSS, IIEF, LUTS, BPH

\begin{abstract}
Abstrak: Lower urinary tract symptoms (LUTS) yang disebabkan oleh benign prostatic hyperplasia (BPH) merupakan suatu kondisi yang sering terjadi pada pria usia lanjut. Selain gejala LUTS, pasien BPH sering juga disertai dengan disfungsi ereksi (DE). Menurut data yang diperoleh dari 30 pasien BPH dengan gejala LUTS dengan menggunakan International prostate symptoms score (IPSS) didapatkan 53,3\% mengalami gejala LUTS dengan derajat berat dan pasien BPH dengan gejala LUTS yang mengalami DE dengan menggunakan skor international index of erectile function (IIEF) ditemukan fungsi ereksi (FE) sebanyak 26,7\% dengan derajat ringan dan berat, fungsi orgasme (FO) sebanyak $40 \%$ dengan derajat berat, hubungan seksual (HS) sebanyak 46,7\% dengan derajat Ringan-sedang, kepuasan seksual (KS) sebanyak 33,3\% dengan derajat berat dan kepuasan menyeluruh (KM) sebanyak 43,3\% dengan derajat ringan. Dengan melakukan penelitian ini, peneliti ingin mengetahui hubungan antara skor IPSS dengan skor IIEF pada pasien BPH dengan gejala LUTS di poli Bedah RSUP Prof. Dr. R. D. Kandou Manado. Berdasarkan hasil uji kolerasi menggunakan spearman untuk mengetahui hubungan antara skor IPSS dengan skor IIEF didapatkan FE (R:0,372), FO (R: 389), HS (R:0,129), KS (R: 0,351), KM (R: 0,84). Dari hasil tersebut dapat dilihat adanya hubungan antara skor IPSS dan skor IIEF.
\end{abstract}

Kata kunci: IPSS, IIEF, LUTS, BPH 
Pasien BPH (Benign Prostatic Hyperplasia) biasanya disertai dengan gejala LUTS (Lower Urinary Tract Symptoms). ${ }^{1,2}$ LUTS adalah kumpulan gejala pada saluran kemih bagian bawah yangterdiri atas gejala voiding, storagedan post miksi. ${ }^{3,4}$ Terdapat beberapa cara untuk menilai berat ringannya gejala LUTS salah satunya dengan menggunakan skor IPSS (International Prostate Symptoms Score) yang direkomendasikan oleh WHO (World Health Organization) dan diambil dari AUA (American Urological Association). ${ }^{4,5}$

Pada pasien BPH dengan gejala LUTS sering juga ditemukan dengan gejala DE (Disfungsi ereksi). Untuk mengidentifikasi DE maka digunakan suatu indeks skor, yaitu IIEF (International Index of Erectile Function). ${ }^{4,6}$

Penelitian yang dilakukan oleh Rosen dkk (2003) tentang kolerasi (R) antara IPSS dengan IIEF didapatkanfungsi ereksi (FE)(R: 0,214), kepuasan seksual (KS)(R: $0.120)$, fungsi orgasme (FO) (R: 0,187), hasrat seksual (HS) (R: 0,149)dankepuasan menyeluruh (KM)(R: 0,138). ${ }^{7}$

Di Indonesia belum banyak yang melakukan penelitian tentang hubungan IPSS dengan IIEF pada pasien BPH dengan gejala LUTS, oleh karena itu penulis ingin melakukan penelitian untuk mencari tahu dan membuktikan apakah ada hubungan antara skor IPSS dan skor IIEF pada pasien BPH dengan gejala LUTS di Poli Bedah RSUP Prof. Dr. R. D. Kandou Manado.

\section{METODE PENELITIAN}

Penelitian ini merupakan penelitian cross-sectional dengan memberikan kuesioner pada pasien BPH dengan gejala LUTS yang datang berobat di poli bedah RSUP Prof. Dr. R. D. Kandou Manado pada bulan Oktober sampai dengan Desember 2014.

\section{HASIL PENELITIAN}

Sampel penelitian yang diperoleh dari Poli Bedah RSUP Prof. Dr. R. D. Kandou bulan Desember 2014, pada pasien BPH dengan gejala LUTS yang memenuhi kriteria inklusi dan kriteria eksklusi berjumlah 30 subjek. Tabel 1 memperlihatkan bahwa usia responden berkisar antara 50-89 tahun. Berdasarkan kelompok umur, pasien BPH dengan gejala LUTS terbanyak pada umur 70-79 tahun yaitu 20 responden $(66,7 \%)$.

Tabel 1. Distribusi pasien BPH dengan gejala LUTS berdasarkan Usia

\begin{tabular}{clcc}
\hline & & Frekuensi & $\%$ \\
\hline \multirow{4}{*}{ Valid } & 50-59 Tahun & 1 & 3,3 \\
& 60-69 Tahun & 6 & 20,0 \\
& 70-79 Tahun & 20 & 66,7 \\
& 80-89 Tahun & 3 & 10,0 \\
& Total & 30 & 100,0 \\
\hline
\end{tabular}

Tabel 2 memperlihatkan bahwa jumlah skor IPSS yang ditemukan pada responden berdasarkan derajat berat-ringannya $\mathrm{BPH}$ dengan gejala LUTS. Pasien BPH dengan gejala LUTS terbanyak adalah derajat berat, yaitu sebanyak 16 responden (53,3\%).

Tabel 2. Distribusi skor IPSS pada pasien BPH dengan gejala LUTS

\begin{tabular}{clcc}
\hline & & Frekuensi & $\%$ \\
\multirow{4}{*}{ Valid } & Ringan & 4 & 13,3 \\
& Sedang & 10 & 33,3 \\
& Berat & 16 & 53,3 \\
& Total & 30 & 100,0 \\
\hline
\end{tabular}

Tabel 3 memperlihatkan bahwa jumlah skor IIEF berdasarkan FE, FO, HS, KS dan $\mathrm{KM}$ yang ditemukan pada pasien BPH dengan gejala LUTS yang mempunyai masalah dengan FE terbanyak ialah disfungsi berat dan disfungsi ringan sebanyak 8 responden (26,7\%). Berdasarkan FO ditemukan terbanyak disfungsi berat sebanyak 12 responden (40,0\%). Berdasarkan HS yang ditemukan terbanyak disfungsi ringan-sedang sebanyak 14 responden (46,7\%). Berdasarkan KS terbanyak disfungsi berat sebanyak 10 responden (33,3\%) dan berdasarkan KM terbanyak disfungsi ringan sebanyak 13 responden (43,3\%). 
Jurnal e-Clinic (eCl), Volume 3, Nomor 1, Januari-April 2015

Tabel 3. Distribusi skor IIEF pada pasien BPH dengan gejala LUTS

\begin{tabular}{clcc}
\hline & & Frekuensi & $\%$ \\
\hline \multirow{4}{*}{ Fungsi } & Disfungsi Berat & 8 & 26,7 \\
Ereksi & Disfungsi Sedang & 5 & 16,7 \\
& Disfungsi Ringan-Sedang & 7 & 23,3 \\
& Disfungsi Ringan & 8 & 26,7 \\
& Tidak ada Disfungsi & 2 & 6,7 \\
\hline \multirow{5}{*}{ Fungsi } & Disfungsi Berat & 12 & 40,0 \\
Orgasme & Disfungsi Sedang & 2 & 6,7 \\
& Disfungsi Ringan-Sedang & 9 & 30,0 \\
& Disfungsi Ringan & 3 & 10,0 \\
& Tidak ada Disfungsi & 4 & 13,3 \\
\hline \multirow{5}{*}{ Hubungan } & Disfungsi Sedang & 9 & 30,0 \\
& Disfungsi Ringan-Sedang & 14 & 46,7 \\
& Disfungsi Ringan & 5 & 16,7 \\
& Tidak ada Disfungsi & 2 & 6,7 \\
\hline \multirow{5}{*}{ Kepuasan } & Disfungsi Berat & 10 & 33,3 \\
& Disfungsi Sedang & 5 & 16,7 \\
& Disfungsi Ringan-Sedang & 9 & 30,0 \\
& Disfungsi Ringan & 5 & 16,7 \\
& Tidak ada Disfungsi & 1 & 3,3 \\
\hline \multirow{5}{*}{ Kepuasan } & Disfungsi Berat & 2 & 6,7 \\
Menyeluruh & Disfungsi Sedang & 7 & 23,3 \\
& Disfungsi Ringan Sedang & 5 & 16,7 \\
& Disfungsi Ringan & 13 & 43,3 \\
& Tidak ada Disfungsi & 3 & 10,0 \\
\hline
\end{tabular}

Untuk melihat ada tidaknya hubungan antara IPSS dan usia dengan IIEF digunakan Spearman pada uji Non Parametrik. Hasil uji kolerasi hubungan IPSS dan usia dengan IIEF pada pasien BPH dengan gejala LUTS di Poli Bedah RSUP Prof. Dr. R. D. Kandou Manado dapat di lihat pada tabel 4.

Tabel 4. Kolerasi skor IPSS dan Usia dengan skor IIEF pada pasien BPH dengan gejala LUTS

\begin{tabular}{|c|c|c|c|c|}
\hline & & & IIEF & USIA \\
\hline \multirow{10}{*}{ Spearman's rho } & \multirow{2}{*}{$\mathrm{FE}$} & $\begin{array}{l}\text { Correlation } \\
\text { Coefficient }\end{array}$ & $372^{*}$ &,$- 369^{*}$ \\
\hline & & Sig. (2-tailed) & 043 & 0,45 \\
\hline & \multirow[t]{2}{*}{ FO } & $\begin{array}{l}\text { Correlation } \\
\text { Coefficient }\end{array}$ & ,389* & -228 \\
\hline & & Sig. (2-tailed) & 034 & ,225 \\
\hline & \multirow{2}{*}{ HS } & $\begin{array}{l}\text { Correlation } \\
\text { Coefficient }\end{array}$ & ,129 &,- 145 \\
\hline & & Sig. (2-tailed) & ,497 & 446 \\
\hline & \multirow[t]{2}{*}{ KS } & $\begin{array}{l}\text { Correlation } \\
\text { Coefficient }\end{array}$ & ,351 &,- 273 \\
\hline & & Sig. (2-tailed) & ,057 & 144 \\
\hline & \multirow{2}{*}{ KM } & $\begin{array}{l}\text { Correlation } \\
\text { Coefficient }\end{array}$ & ,084 &,- 190 \\
\hline & & Sig. (2-tailed) & 658 & ,314 \\
\hline
\end{tabular}


Dari Tabel 4 dapat dilihat nilai kolerasi IPSS dengan FE (R:0,372), FO (R: 389), HS (R:0,129), KS (R: 0,351), KM (R: 0,84) dengan arah positif dan didapatkan nilai signifikansi pada beberapa variabel $>0,05$ seperti pada variabel IPSS dengan HS, KS, $\mathrm{KM}$, akan tetapi pada variabel IPSS dengan FE dan FO di dapatkan nilai signifikansi $<0,05$ yang berarti adanya kolerasi antara variabel FE dan FO terhadap IPSS. Nilai kolerasi yang diterima ialah antara -1 dan 1 , yang berarti terdapat korelasi dan untuk nilai signifikansi yang memiliki kolerasi yang bermakna ialah pada nilai signifikansi $<0,05$.

Hubungan antara usia dengan skor IPSS dan skor IIEF hampir tidak ditemukan adanya hubungan, hanya pada FE yang memiliki nilai kolerasi -0,369 yang berada di berada dalam nilai kolerasi -1 sampai 1 dan nilai signifikansi $<0,05$ dengan arah negatif.

Untuk melihat perbandingan dari skor IPSS dan IIEF digunakan Wilcoxon test. Hasil perbandingan dari Wilcoxon dapat dilihat pada tabel 5 dan tabel 6 .

Dari tabel 6 nilai $\mathrm{Z}$ dari semua variabel IIEF menunjukan nilai sebesar -3.355 (FE), -4.784 (FO),-4,703 (HS),-4,683 (KS) dan 4,490 (KM). Dengan menetapkan level signifikansi $<0.05$ dan menggunakan uji dua sisi, maka diperoleh nilai penerimaan ho antara -1,96 sampai 1,96. Dengan demikian hasil test menggunakan Wilcoxon didapatkan h0 ditolak dan h1 diterima, karna nilai z berada di luar -1,96 sampai 1,96 dan di dukung dengan nilai signifikansi $<0,05$ dari setiap variabel.

Tabel 5. Ranks Wilcoxon

\begin{tabular}{llccc}
\hline & & $\mathrm{N}$ & $\begin{array}{c}\text { Mean } \\
\text { Rank }\end{array}$ & $\begin{array}{c}\text { Sum of } \\
\text { Ranks }\end{array}$ \\
\hline \multirow{3}{*}{ IPSS - FE } & Negative Ranks & $5^{\mathrm{a}}$ & 12,50 & 62,50 \\
& Positive Ranks & $24^{\mathrm{b}}$ & 15,52 & 372,50 \\
& Ties & $1^{\mathrm{c}}$ & & \\
IPSS - FO & Negative Ranks & $0^{\mathrm{d}}$ &, 00 &, 00 \\
& Positive Ranks & $30^{\mathrm{e}}$ & 15,50 & 465,00 \\
& Ties & $0^{\mathrm{f}}$ & & \\
IPSS - HS & Negative Ranks & $2^{\mathrm{g}}$ & 2,00 & 4,00 \\
& Positive Ranks & $28^{\mathrm{h}}$ & 16,46 & 461,00 \\
& Ties & $0^{\mathrm{i}}$ & & \\
IPSS - KS & Negative Ranks & $1^{\mathrm{j}}$ & 1,00 & 1,00 \\
& Positive Ranks & $28^{\mathrm{k}}$ & 15,50 & 434,00 \\
& Ties & $1^{\mathrm{l}}$ & & \\
IPSS - KM & Negative Ranks & $4^{\mathrm{m}}$ & 2,50 & 10,00 \\
& Positive Ranks & $25^{\mathrm{n}}$ & 17,00 & 425,00 \\
& Ties & $1^{\mathrm{o}}$ & & \\
\hline
\end{tabular}

a. IPSS $<$ FE, b. IPSS $>$ FE, c.IPSS $=$ FE, d.IPSS $<$ FO, eIPSS $>$ FO, f.IPSS $=$ FO, g.IPSS $<$ HS, h. IPSS $>$ HS, i.IPSS $=H S$, j. IPSS $<$ KS, k. IPSS $>$ KS, l. IPSS=KS, m.IPSS $<$ KM, n. IPSS $>$ KM, o.IPSS $=K M$, 
Tabel 6. Uji statistik Wilcoxon

\begin{tabular}{|c|c|c|c|c|c|}
\hline & $\begin{array}{c}\text { IPSS - } \\
\text { FE }\end{array}$ & $\begin{array}{l}\text { IPSS - } \\
\text { FO }\end{array}$ & $\begin{array}{c}\text { IPSS - } \\
\text { HS }\end{array}$ & $\begin{array}{l}\text { IPSS } \\
-\mathrm{KS} \\
\end{array}$ & $\begin{array}{c}\text { IPSS } \\
-\mathrm{KM} \\
\end{array}$ \\
\hline Z & $-3,355^{b}$ & $-4,784^{b}$ & $-4,703^{b}$ & $\begin{array}{r}- \\
4,683 \\
\text { b }\end{array}$ & $\begin{array}{r}- \\
4,490 \\
\text { b }\end{array}$ \\
\hline $\begin{array}{l}\text { Asymp. Sig. (2- } \\
\text { tailed) }\end{array}$ & 001 & 000 & 000 & 000, & ,000 \\
\hline
\end{tabular}

h0: tidak terdapat hubungan antara kenaikan skor IPSS dengan penurunan skor IIEF h1: terdapat hubungan antara kenaikan skor IPSS dengan penurunan skor IIEF

\section{BAHASAN}

BPH dengan gejala LUTS umunya ditemukan pada pria usia lanjut. ${ }^{8,9}$ Berdasarkan penelitian yang dilakuakan di Poli Bedah RSUP Prof. Dr. R. D. Kandou Manado pada 30 pasien BPH dengan gejala LUTS berat, sebanyak 20 responden (66,7\%) berdasarkan kelompok usia 70-79 tahun dan kedua terbanyak pada kelompok usia 60-69 tahun sebanyak 6 responden (20,0\%). Tidak jauh berbeda dengan penelitian yang di lakukan oleh Ozayar (2008) pasien BPH terbanyak pada kelompok usia 70-79 dan 80-89 tahun dibandingkan usia 60-69 tahun. ${ }^{10}$ Di Klinik Urologi RSUP Arifin Achmad Provinsi Riau kelompok usia terbanyak 60-69 tahun sebanyak 23 responden dari 60 pasien $\mathrm{BPH}$ (38,3\%) dan yang terbanyak kedua pada kelompok usia 70-79 tahun sebanyak 17 responden (28,8\%). ${ }^{11}$

Penentuan derajat BPH menggunakan skor IPSS dengan interpretasi 0-7 derajat ringan, 8-19 derajat sedang, dan 20-35 derajat berat. Denganmengetahui jumlah skor kita dapat menilai keadaan pasien, membantu diagnosis dini dan juga mempertimbangkan penatalaksanaan yang tepat untukpasien., ${ }^{4,5}$

Distribusi frekuensi pasien $\mathrm{BPH}$ dengan gejala LUTS dengan menggunakan IPSS di Poli Bedah RSUP Prof. Dr. R. D. Kandou Manado didapatkan derajat BPH yang paling banyak ditemukan adalah derajat berat sebanyak 16 responden (53,3\%). Sama halnya dengan penelitian yang dilakukan di Klinik Urologi RSUP Arifin Achmad Provinsi Riau didapatkan skor IPSS terbanyak dengan derajat berat sebanyak 32 responden $(53,3 \%){ }^{11}$ Fenomena besarnya insiden pasien BPH datang dengan gejala LUTS berat, dikarenakan pasien BPH datang mencari pengobatan diakibatkan gangguan LUTS yang dialami sudah sangat mengganggu dan semakin berat. ${ }^{12}$

DE atau yang lebih dikenal sebagai impoten merupakan masalah seksual pada pria. DE ialah ketidak mampuan memperoleh ereksi secara adekuat untuk mencapai aktifitas seksual. ${ }^{13}$ Untuk mengidentifikasi DE digunakan IIEF. IIEF memiliki 15 pertanyaan tentang masalah ereksi selama satu bulan terakhir yang terdiri dari fungsi ereksi (P 1-5, 15), fungsi orgasme (P 9,10), hubungan seksual ( $P$ 11,12), kepuasanseksual (P 68)dankepuasan menyeluruhan (P 13-14). ${ }^{6,14}$ Interpretasi skor IIEF adalah sebagai berikut total skor dari $\mathrm{FE}$ adalah sebagai berikut 0-6 disfungsi berat, 7-12 disfungsi sedang, 13-18 disfungsi ringan sampai sedang, 19-24 disfungsi ringan, 25-30 tidak ada disfungsi, total skor FO, HS, KM adalahsebagai berikut $0-2$ disfungsi berat, 3-4 disfungsi sedang, 5-6 disfungsi ringan sampai sedang, 7-8 disfungsi ringan, 9-10 tidak ada disfungsi dan total skor KS adalah sebagai berikut 0-3 disfungsi berat, 4-6 disfungsi sedang, 7-9 disfungsi ringan sampai sedang, 10-12 disfungsi ringan, 1315 tidak ada disfungsi. $4,6,15$ 
Distribusi Frekuensi pasien BPH dengan gejala LUTS yang mengalami DE menggunakan skor IIEF di Poli Bedah RSUP Prof. Dr. R. D. Kandou Manado yaitu IIEF (FE) terbanyak yaitu Disfungsi ringan dan berat sebanyak 8 responden (26,7\%), IIEF (FO) terbanyak dengan derajat berat sebanyak 12 responden (40,0\%), IIEF (HS) terbanyak derajat ringan-sedang sebanyak 14 responden (46,7\%), IIEF (KS) terbanyak derajat berat sebanyak 10 responden (33,3\%) dan IIEF (KM) terbanyak dengan derajat ringan sebanyak 13 responden (43,3\%).

Menurut multi-national survey of the aging male (MSAM-7) dilaporkan bahwa fungsi ereksi akan menurun secara bermakna seiring dengan bertambah beratnya derajat LUTS pada pasien $\mathrm{BPH}^{7}$

Penelitian yang di lakukan di Poli Bedah RSUP Prof. Dr. R. D. Kandou Manado pada 30 pasien BPH dengan gejala LUTS untuk mengetahui hubungan antara skor IPSS dan skor IIEF ditemukan hubungan antara skor IPSS dan IIEF. Dengan menggunakan uji kolerasi spearman didapatkan kolerasi yang cukup kuat dengan arah positif antara skor IPSS dengan skor IIEF, kolerasi yang didapatkan untuk IPSS dengan IIEF(FE) sebesar 0,372, IIEF (FO) sebesar 0,389, IIEF (HS) sebesar 0,129, IIEF (KS) sebesar 0,351 dan IIEF (KM) sebesar 0,84. Dapat di lihat dari hasil kolerasi yang tidak lebih 1 dan -1. Dan untuk mendukung hasil dari test spearmen di gunakan test willcoxon untuk melihat apakah semakin besar skor IPSS maka skor IIEF semakin kecil. Dapat dilihat test statistics willcoxon nilai $\mathrm{Z}$ dari semua variabel IIEF menunjukan nilai sebesar 3.355 (FE), -4.784 (FO),-4,703 (HS),-4,683 (KS),-4,490 (KM) dan di dukung dengan nilai signifikansi $<0.05$ dan menggunakan uji dua sisi. Nilai Z kritis antara -1.96 dan 1.96, yang berarti berada di daerah penerimaan tidak terdapat korelasi besar skor IPSS dan IIEF.

Tidak jauh berbeda dengan penelitian yang di lakuakan oleh Rosen dkk menunjukan hubungan IPSS dengan IIEF yaitu, FE(R: 0,214), KS(R: 0.120), FO(R:
0,187), $\quad H S(R: \quad 0,149), \quad \operatorname{danKM}(\mathrm{R}$ : $0,138) .{ }^{12}$ Sedangkan pada penelitian yang dilakukan oleh J.W Huangdkk di peroleh kolerasi dari IPSS dan IIEF sebagai berikut FE (R:-0,202), FO (R:-249), HS (R:-0,90), KS (R:-0,210) dan KM (R:-0,147). ${ }^{16}$

Penelitian ini memiliki kelemahan dalam penentuan usia sebagai faktor resiko yang menyebabkan DE, peneliti tidak dapat mengelompokan berdasarkan kelompok usia dengan DE dikarenakan data yang kurang dan waktu penelitian yang singkat. Sehingga untuk menyingkirkan faktor resiko usia sebagai penyebab dari DE pada penelitian yang dilakukan di Poli Bedah RSUP Prof. Dr. R. D. Kandou dilakukan uji spearman untuk mengetahui hubungan antara usia dengan skor IPSS dan skor IIEF dilakukan tanpa melakukan pembagian kelompok usia dan didapatkan hubungan usia dengan skor IIEF yang sangat lemah antara usia dengan skor IPSS dan skor IIEF, sehingga dapat disingkirkan faktor usia sebagai penyebab DE.

Dengan diketahuinya hubungan antara skor IPSS dengan skor IIEF atau pasien BPH dengan gejala LUTS dan DE, dan menjadi titik tolak untuk melakukan screening fungsi seksual khususnya fungsi ereksi pada pasien BPH dengan gejala LUTS. Sehingga dapat diharapkan untuk membantu diagnosis dan penatalaksanaan sedini mungkin pada pasien.

\section{SIMPULAN}

Dari hasil penelitian telah diketahui distribusi pasien BPH dengan gejala LUTS berdasarkan usia, skor IPSS, skor IIEF, hubungan dan perbandingan antara skor IPSS dengan skor IIEF dimana semakin besar skor IPSS maka skor IIEF semakin kecil. Sehingga dapat di simpulkan pasien $\mathrm{BPH}$ dengan gejala LUTS berat mengalami DE yang berat. Dan terdapat hubungan antara skor IPSS dan skor IIEF.

\section{SARAN}

Pria yang berusia lebih dari 40 tahun agar memeriksakan diri sedini mungkin bila mengalami gangguan buang air kecil seperti buangair kecil tidak tuntas, 
mengejan, sulit untuk menahan kencing, pancaran kencing lemah dan terputusputus. Untuk membantu diagnosis dini dapat digunakan skor IPSS dan skor IIEF yang dapat digunakan oleh dokter maupun pasien. Untuk peneliti perlu untuk

memperhatikan secara lebih teliti pasien BPH dengan gejala LUTS mengalami DE atau DE dikarenakan oleh usia.

\section{DAFTAR PUSTAKA}

1. Yoo TK, Cho HJ. Benign prostatic hyperplasia: From bench to clinic. Korean J Urol. 2012;53:139-48.

2. Kirby R, Lepor H. Evaluation and non surgical management of benign prostatic hyperplasia. In: Walsh PCa et al. Campbell's Urology, 9th ed. 2007;87.

3. Gammack JK. Lower urinary tract symptoms. Clinics in Geriatric Medicine. 2010. p. 249-60.

4. Purnomo BB. Dasar-Dasar Urologi. Edisi ketiga. Malang: Sagung Seto; 2011.127-8.

5. Matthew BG, Alan W Partin, David YC. Lower Urinary Tract Symptoms (LUTS) and Benign Prostatic Hyperplasia (BPH). In: Robert G Moore, Jay T Bishoff, Stefan Loenig, Steven G Docimo, eds. Minimally Invasive Urological Surgery. USA: Taylor and Francis Group plc; 2005. p.545.

6. Rosen R, Riley A, Wagner G, et al. The International Index of Erectile Function (IIEF): A Multidimensional scale for assessment of erectile dysfunction. Urology, 1997, 49: 82230.

7. Rosen R, Altwein J, Boley P, et.al. Lower Urinary Tract Symptoms and Male Sexual Dysfunction: The Multinational Survey of the Aging Male (MSAM-7). Eur Urol. 2003;44:637-49.

8. Sarma AV, Wei JT: Clinical practice. Benign prostatic hyperplasia and lower urinary tract symptoms. N Engl J Med 2012, 367: 248-257.

9. Platz EA, Joshu CE, Mondul AM, Peskoe SB, Willett WC, Giovannucci E: Incidence and progression of lower urinary tract symptoms in a large prospective cohort of United States men. J Urol 2012, 188: 496 - 501.

10.Ozyar A, Zumrutbas A, Yaman O. The Relationship between Lower Urinary Tract Symptoms, Diagnostic Indicator of Benign Prostatic Hyperplasia (BPH), and Erectile Dysfunction in Patients with Moderate to Severely Symptomatic BPH. Int Urol Nephrol. 2008;40: 9339.

11.Fitriana N, Zuhirman, Suyanto.hubungan Benign prostate hypertrophy dengan disfungsi ereksi di RSUD Arifin Achmad Provinsi Riau. Fakultas kedokteran universitas Riau. 2014;112.

12.Utomo NB, Birowo $P$, Rasyid N, Taher N. Disfungsi Ereksi pada Pasien Benign Prostatic Hyperplasia dengan Lower Urinary Tract Symptoms. Jurnal Ilmu Bedah Indonesia. 2012;39-40(12):13-15.

13.McVary KT, Roehrborn CG, Avins AL, Barry MJ, Bruskewitz RC, Donnell RF, et al. Update on AUA guideline on the management of benign prostatic hyperplasia. $\mathrm{J}$ Urol. 2011;185:1793-1803.

14.Clint E. Bruess, Dean Emeritus, Elizabeth Schroeder. Sexuality Education Theory and Practice. 6th ed. England: Jones \& Bartlett Publishers; 2013.

15.Emil Tanagho, Jack WM. editors. Smith's General Urology Seventeenth Edition. USA: The McGraw-Hill Companies,Inc; 2008.

16. Huang WJ, Chen KK, Chang LS. Correlation between voiding and erectile function in patients with symptomatic benign prostatic hyperplasia. J Chinese Med Assoc. 2005;68:178-82. 